Kalpa Publications in Engineering
Volume 1, 2017, Pages 103-114
ICRISET2017. International Conference on Re-
search and Innovations in Science, Engineering
\&Technology. Selected Papers in Engineering

\title{
The HTS Cable Under Fault Conditions in a Power System
}

\author{
Tarun Patel and Anuradha Deshpande \\ The department of Engineering and Technology,Electrical and Electronics,MSU of Baroda \\ Vadodara,Gujarat,India \\ pateltarun444@gmail.com, anuradhasdeshpande62@gmail.com.
}

\begin{abstract}
In today's world electric power demand is increase steadily. In order to meet this increasing demand superconducting cable can be use instead of conventional AC cable in the power system. The Superconducting cable has some different characteristic than conventional AC cable. If this cable is installed in the power system, then there are some effects introduced on the fault current level. These effects on the fault current level can further have an impact on the power system protection. So there is a need to analyze the impact of a superconducting cable on power system protection and determine its impedance under a fault condition. This paper presents the impacts of the fault current level on a superconducting cable under fault condition in power system. Different types of fault are present in this paper like LG fault, LL fault, LLG fault, LLL fault.

Keywords-HTS cable, the Fault current, power system protection.
\end{abstract}

\section{Introduction}

Electric power demand is expected to grow steadily. In order to meet the increasing demand for electricity and maintain the reliability of power system there are different methods are used in power system. The High temperature superconducting (HTS) cable is a newly developed technique to meet the increasing demand of electricity and reliability in power system. The discovery of high temperature superconductor has raised to renew power transmission and distribution cables using a superconducting cables. The reason of using superconducting cable is its compactness, low 
impedance and can transmit a large amount of electric power with a small amount of power loss. With its compact in nature, the overall construction cost of HTS cable is smaller than that of a conventional cable. High temperature superconducting cables, for huge amount of power transmission and distribution, has an benefits of efficiency and operational advantages due to the use of liquid nitrogen for cooling, which represents a low cost and environmental friendly medium.

However, the HTS cable, with lower impedance than that of a conventional AC cable under fault condition, may cause several problems for power system protection by increasing the fault current level in HTS cable. Due to this high fault current level, the breaking capacity of protective devices exceeds.

In order to reduce fault current levels, the HTS cable with a fault current limiting function has been recently developed. The change in fault current level due to the HTS cable can have a negative impacts on the operation of overcorrent relays, which are used to protect the power system. Overcorrent relay has inverse-time characteristics, so there may be a problem when setting time of a backup relay operates faster than a primary relay. The operating time of the back-up protection must be delayed by an appropriate amount over that of the primary protection. Thus, the operating time of the back-up protection should be equal to the operating time of primary protection plus the operating time of the primary circuit breaker. So But using fault current limiting function the fault current level going to higher value at which back-up protection operate first. There for back-up protection operate faster than primary protection. so, the impedance of the fault current limiting HTS cable during the fault must be determined by considering the change in the fault current level and the operation of overcorrect relays.

This paper presents impacts of the fault current on High temperature superconducting cable during fault condition. The computer based MATLAB simulation is needfully applied to the HTS cable in the power system. The effects of fault current due to HTS cable and the conventional cable are defined based on the MATLAB simulation model, and the results are discussed in details. Paper has developed characteristic of HTS cable.

\section{Problem Formulation}

The HTS cable with higher power transfer capacity is designed to have low impedance during the fault condition in power system. Low impedance of the HTS cable under fault condition may cause problems for the power system protection by increasing the fault current. In this section, the impacts of the fault current on the superconducting cable in power system protection are discussed.

\section{1) HTS cable in the power system}

The high temperature superconducting cable core consists of conducting layer and stabilizer. The conducting layer is made of HTS tapes which are utilized to transfer a large amount of electric power to high demand areas. In normal operation, low impedance of the conducting layer transfer large amount of power through HTS cable. When fault occurs in power system, fault current flows through the stabilizer of HTS cable. Because of low impedance of stabilizer, there are a large amount of fault current generate. So the temperature of HTS cable is sharply increased, inducing a performance degradation of the HTS cable. The impedance of the stabilizer is too low to provide a fault current limiting capability to the HTS cable. 
The HTS cable with fault current limiting quality requires a modified HTS cable design with high impedance under fault conditions or other paths for the fault current flow. The Modified structure of HTS cable is designed to reduce the area of the stabilizer in the HTS cable. As the scale of the fault current constantly increase there is a limit to increase the impedance of the HTS cable by reducing the area of stabilizer. In order to overcome this problem fault current limiting (FCL)-HTS cable proposed to include current limiting impedance in additional path. Therefore, there is no need for reducing the area of the stabilizer in the FCL-HTS cable. It is the need to install current limiting impedance in additional path and the fast switch to limit the fault current in the FCL-HTS cable. As standards for testing of SFCLs are not available yet, distinguished efforts are undertaken by the activity of the CIGRE working groups D.1.38 "Emerging Test Techniques Common to High Temperature Superconducting (HTS) Power Applications" and the IEEE Working Group P37.302 on Fault Current Limiter which develops a comprehensive guide for the testing procedure.

\section{2) Impact of HTS cable on power system protection}

The use of HTS power cable with lower impedance can increase the fault current in the power system by decreasing the equivalent power system impedance. This increased fault current again impact on power system protection. To prevent this problem introduced the fault current limiting HTS cable with higher impedance under the fault condition.

The Over current relay is generally used to protect the cable under the fault condition in power system. This change in level of fault current has further impact on over current relay coordination. The settings of over current relays are set previously, but using a HTS cable with a fault current limiting function, the impedance of HTS cable is increased and the relay settings are disturbed. Back up relay operates faster than over current relay. If the fault current level is change due to the installation of HTS cable, then the pre-determined relay settings need to be changed, again which are preventing the relay maloperation.

\section{IMPLEMENTATION OF MATLAB TEST SYSTEM}

\section{a) $22.9 \mathrm{kv}$ test system with HTS cable}

Fig1. Shows the simple block diagram of the electric power transmission system with HTS cable. here $0.5 \mathrm{~km}, 22.9 \mathrm{KV}$ and 50 MVA HTS power cable is considered. The specification of HTS cable is shown in Table I. As shown in Fig. that $154 \mathrm{KV}$ three phase source is used to supply electric power to the three phase load. A three phase fault block is used to create different types of fault. Here we can consider different types of faults.

Fig 2. Shows the simple circuit diagram of the electric power transmission system without HTS cable. Here the length of transmission line is $50 \mathrm{~km}$, which is higher than HTS cable and Resistance of transmission line is also higher than HTS cable. 
The HTS Cable Under Fault Conditions in a Power System Tarun Patel and Anuradha Deshpande

Table 1 :Specification of HTS cable

\begin{tabular}{|l|l|}
\hline Specification & Value \\
\hline Voltage & $22.9 \mathrm{KV}$ \\
\hline Rated current & $1261 \mathrm{~A}$ \\
\hline Length & $0.5 \mathrm{~km}$ \\
\hline HTS Cable structure & 3 phase \\
\hline Resistance & $0.0084 \Omega$ \\
\hline Reactance & $0.0414 \Omega$ \\
\hline Impedance & $0.0422 \Omega$ \\
\hline
\end{tabular}

\section{Experiment Result}

The proposed method has been tested by implementing it on a $22.9 \mathrm{KV}$ test system with different types of fault on the HTS cable. The results obtain using the proposed method, have been compared with the reference [1]. Different types of fault for HTS cable and without the HTS cable are as below,

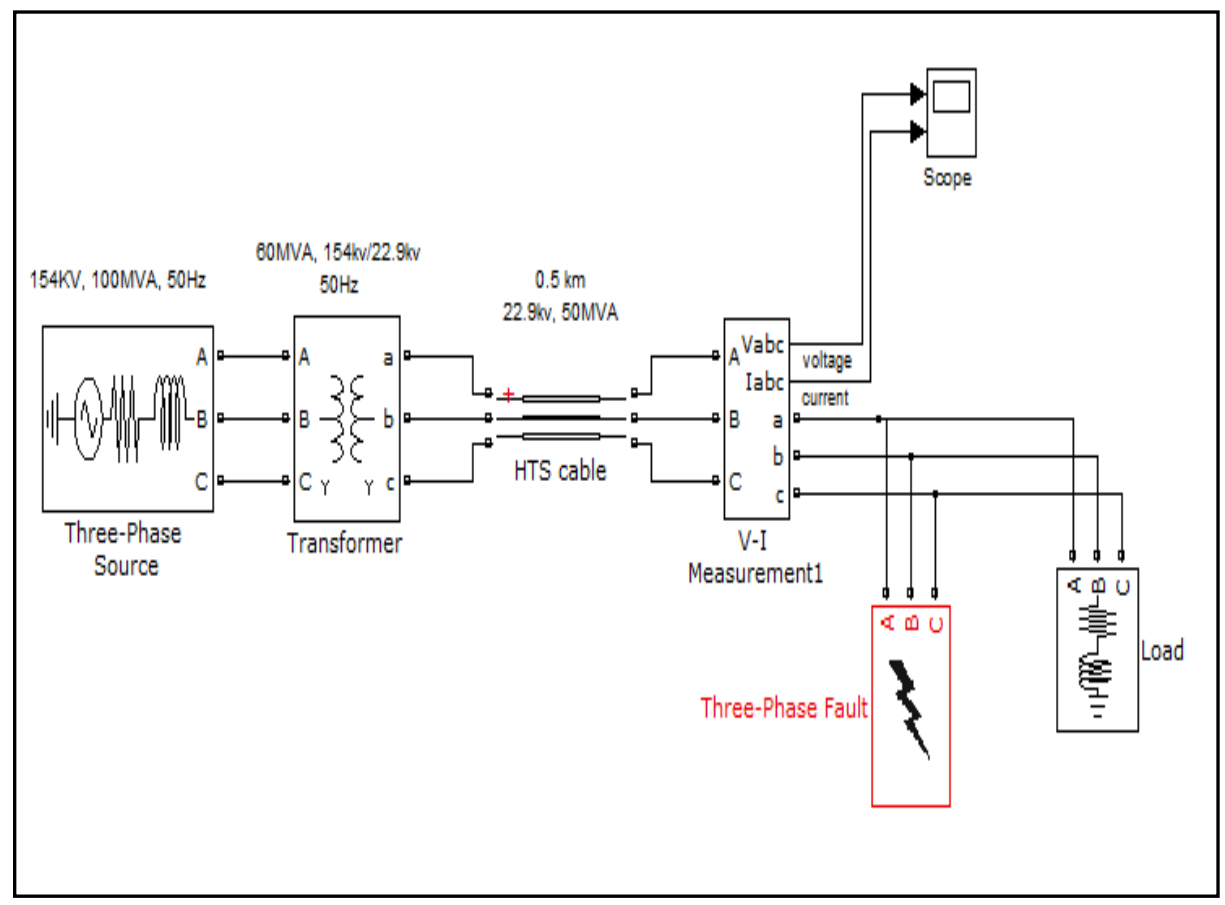

Figure 1. The Line diagram of a $22.9 \mathrm{KV}$ power transmission system with HTS cable 


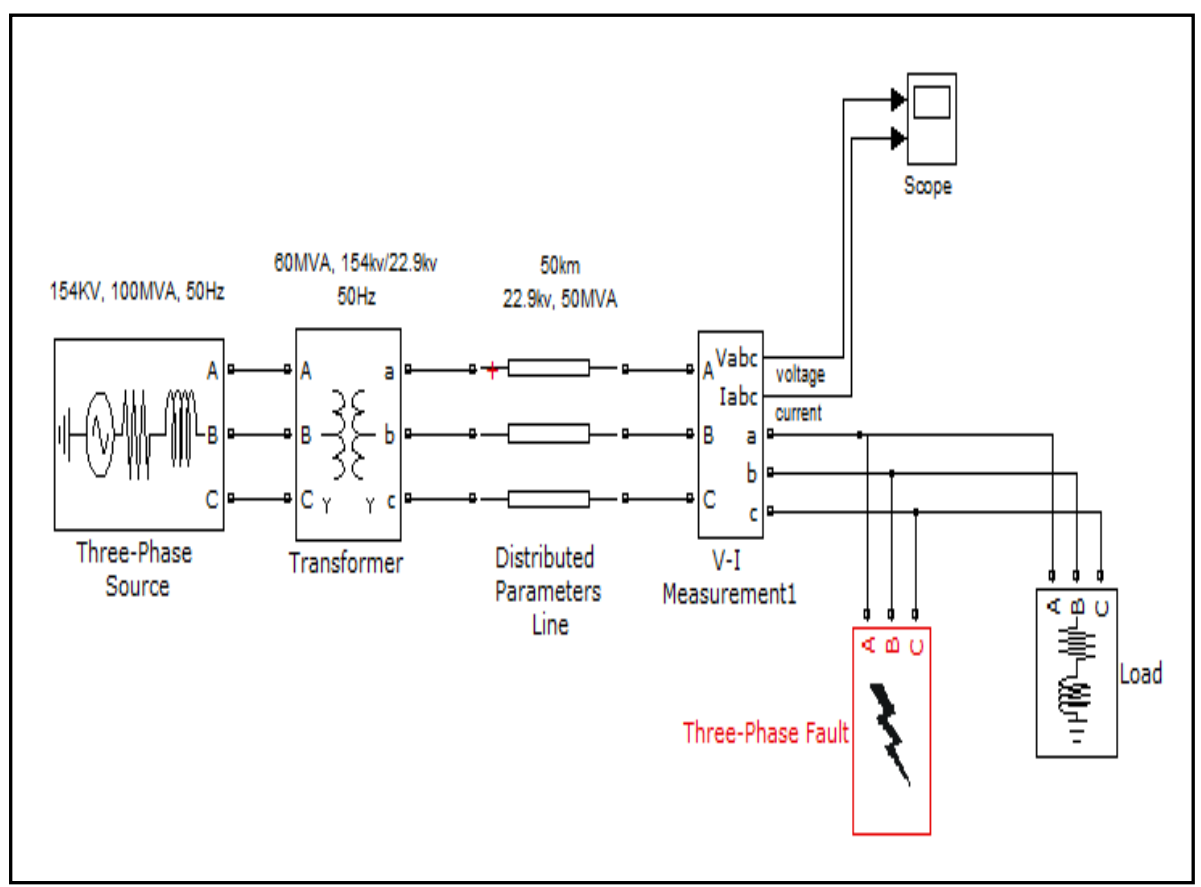

Figure. 2. The Line diagram of $22.9 \mathrm{KV}$ power transmission system without HTS cable

\section{A. Results of fault current with HTS cable}

A. Single line to ground fault

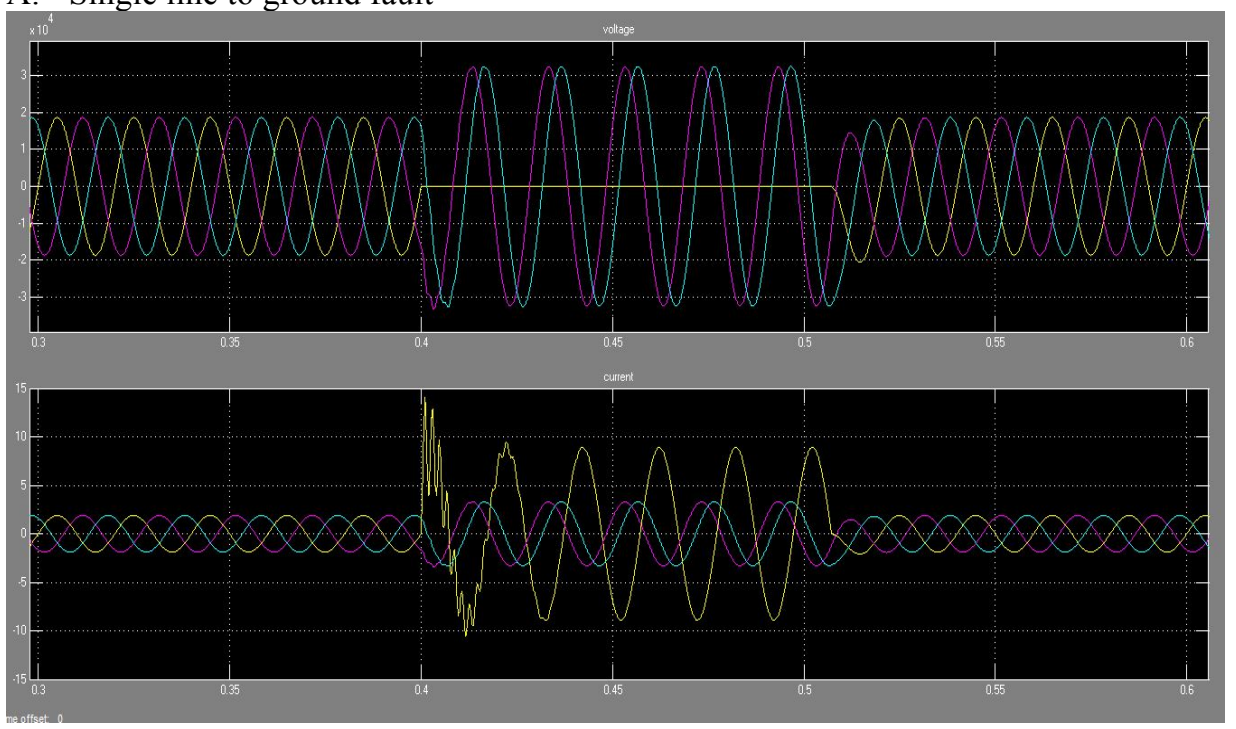

Figure. 3 The Result of a single line to ground fault 
The HTS Cable Under Fault Conditions in a Power System Tarun Patel and Anuradha Deshpande

B. Line to Line fault

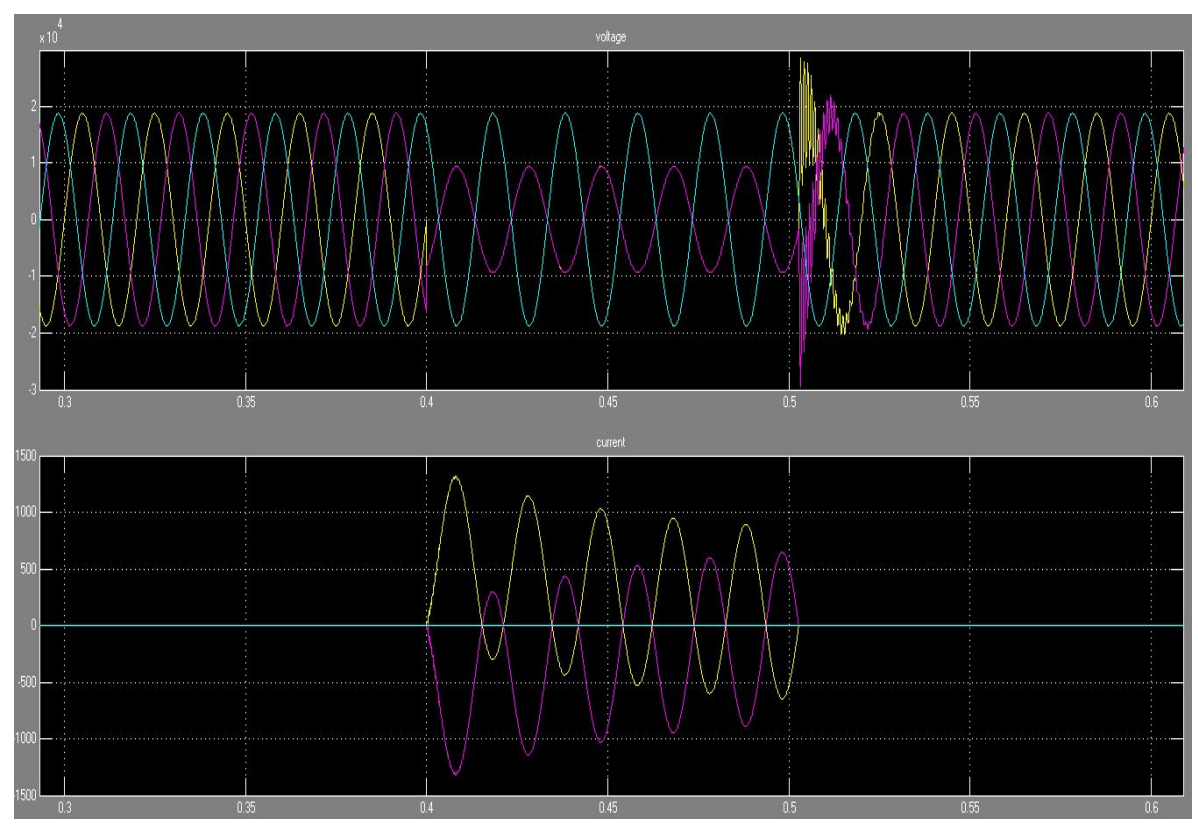

Figure. 4 The Result of line to line fault

C. Double Line to ground fault

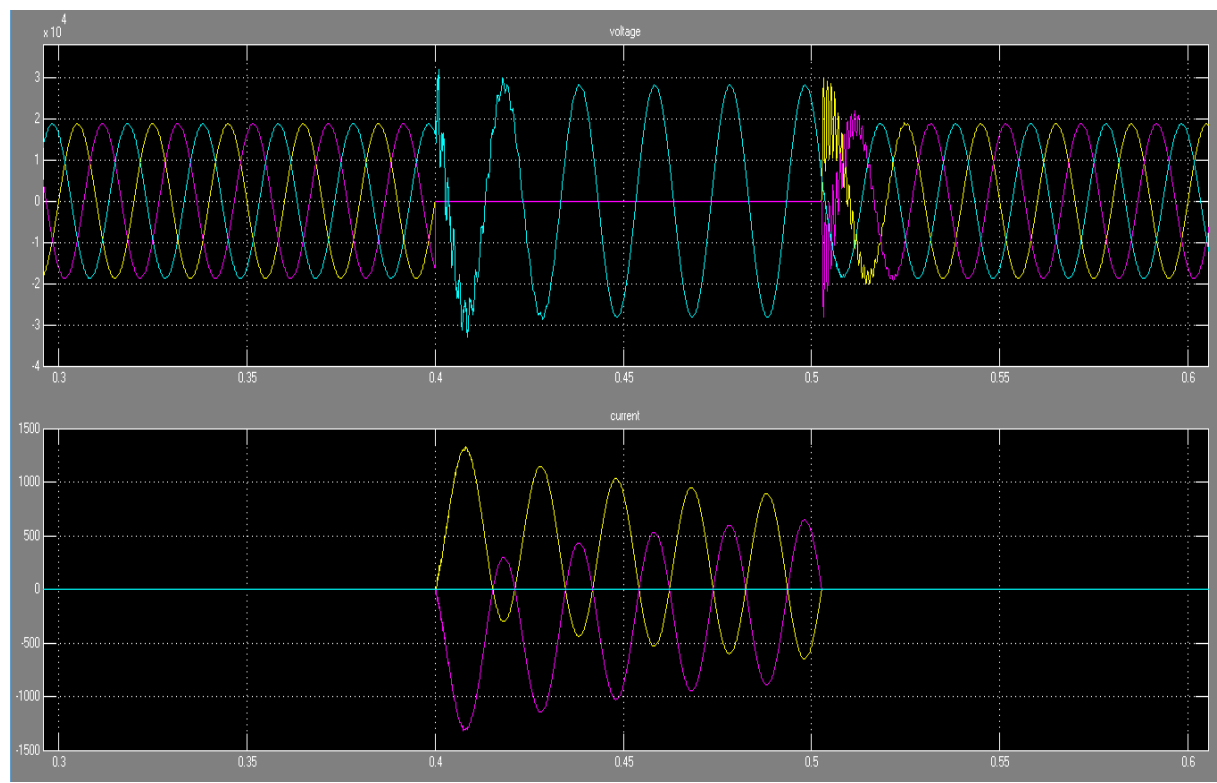

Figure. 5 The Result of double line to ground fault 
D. Three phase fault

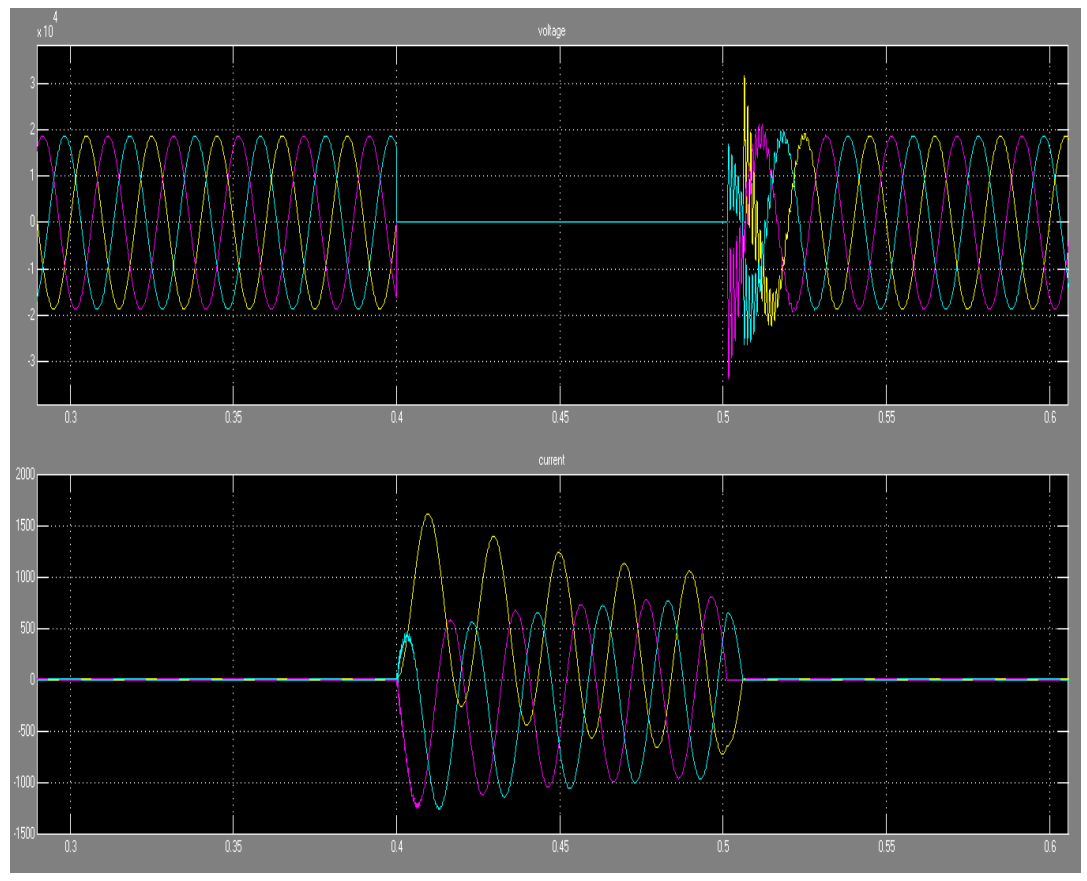

Figure 6 The Result of three phase fault

\section{A. Results of fault current without HTS cable}

1. Single line to ground fault

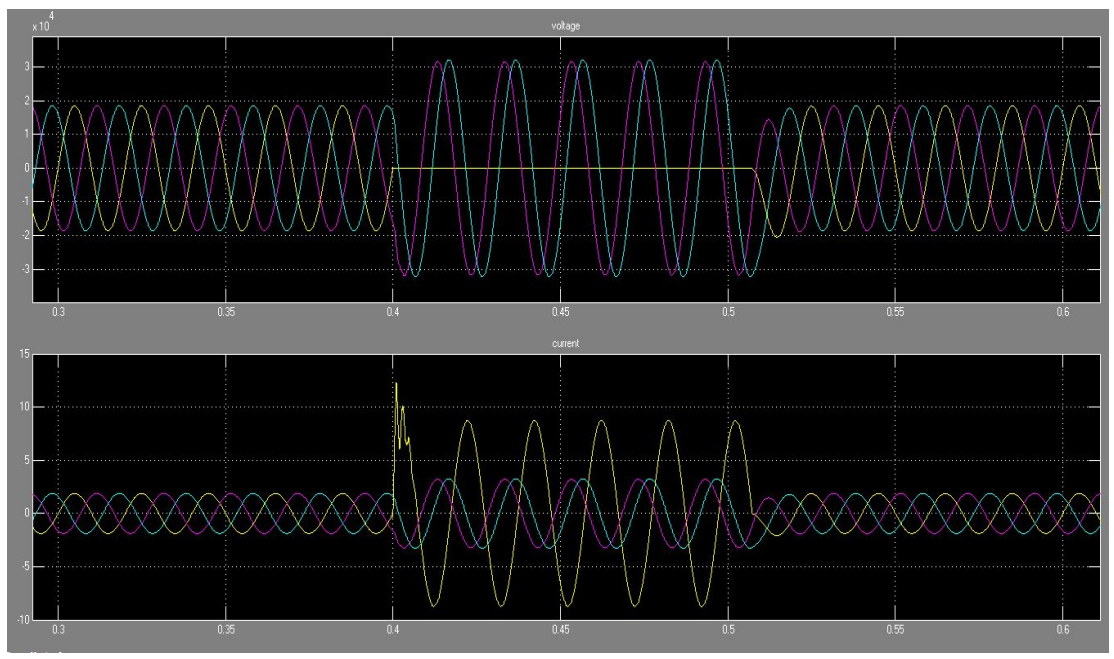

Figure. 7 The Result of a single line to ground fault 
The HTS Cable Under Fault Conditions in a Power System Tarun Patel and Anuradha Deshpande

2. Line to Line fault

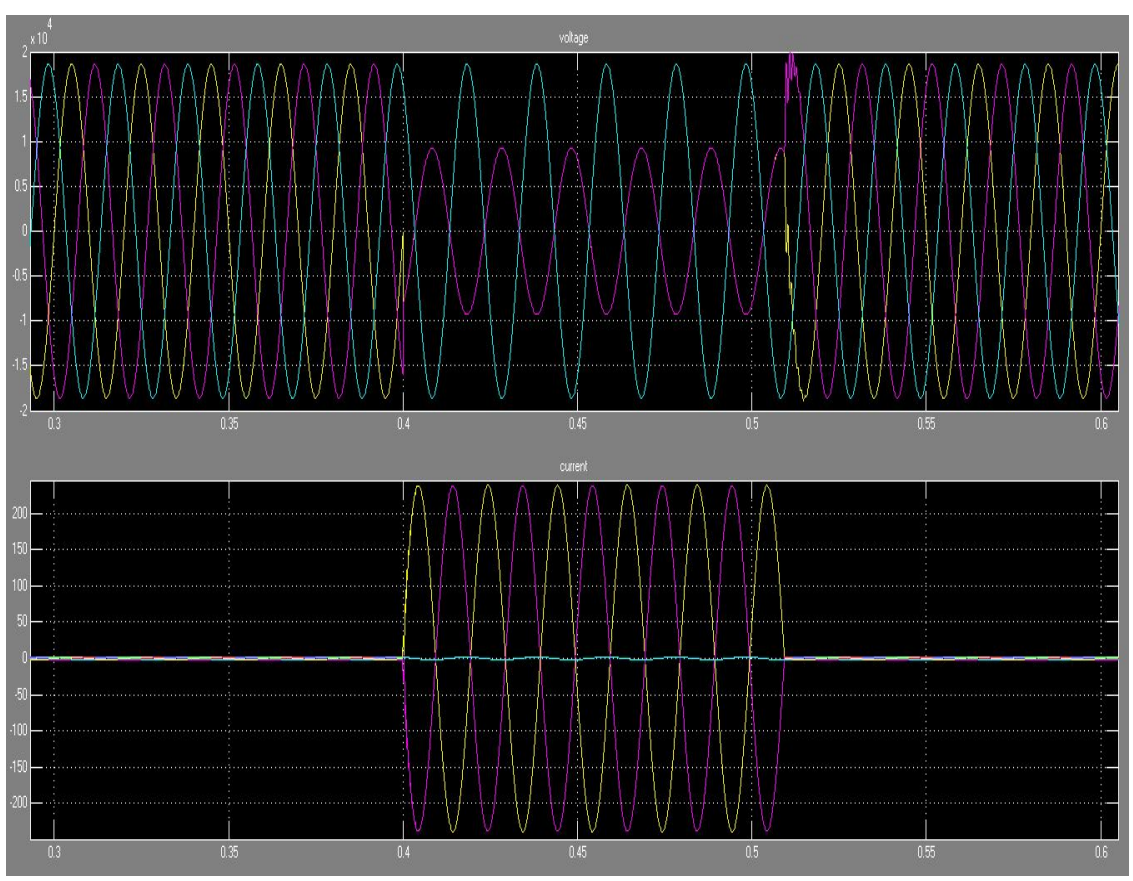

Figure. 8 The Result of line to line fault

3. Double Line to ground fault

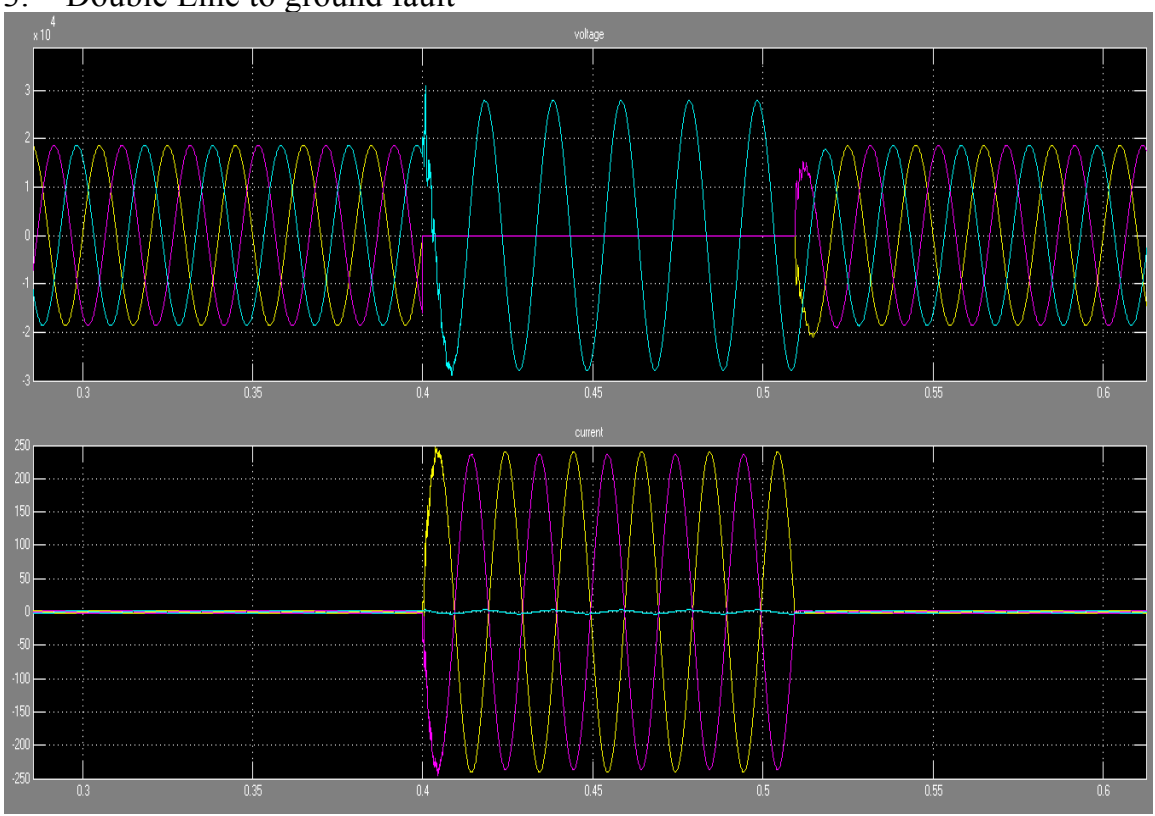

Fig. 9 Result of double line to ground fault 
4. Three phase fault

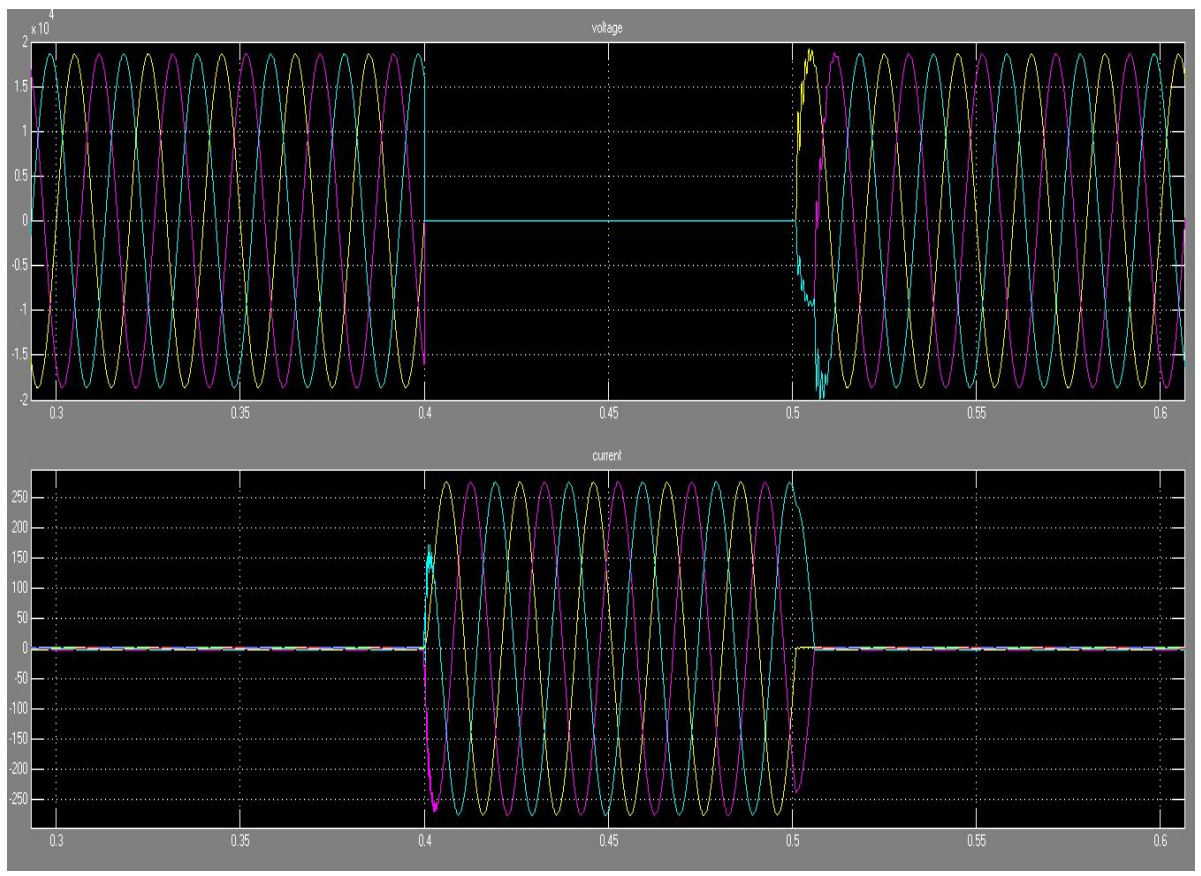

Figure. 10 Result of three phase fault

\section{Comparison and Analysis}

The method has been implemented on 50 MVA test system given in reference paper [1]. The results show in above are obtained and are compared with the result given in reference paper [1]. In reference paper [1], triad co-axial HTS cable and conventional AC cable with $1 \mathrm{~km}$ length and 50 MVA load are used. Triad co-axial HTS cable is designed based on RTDS system with a real length of $0.5 \mathrm{~km}, 22.9 \mathrm{KV} / 50$ MVA HTS cable. 
1) Single line to ground fault

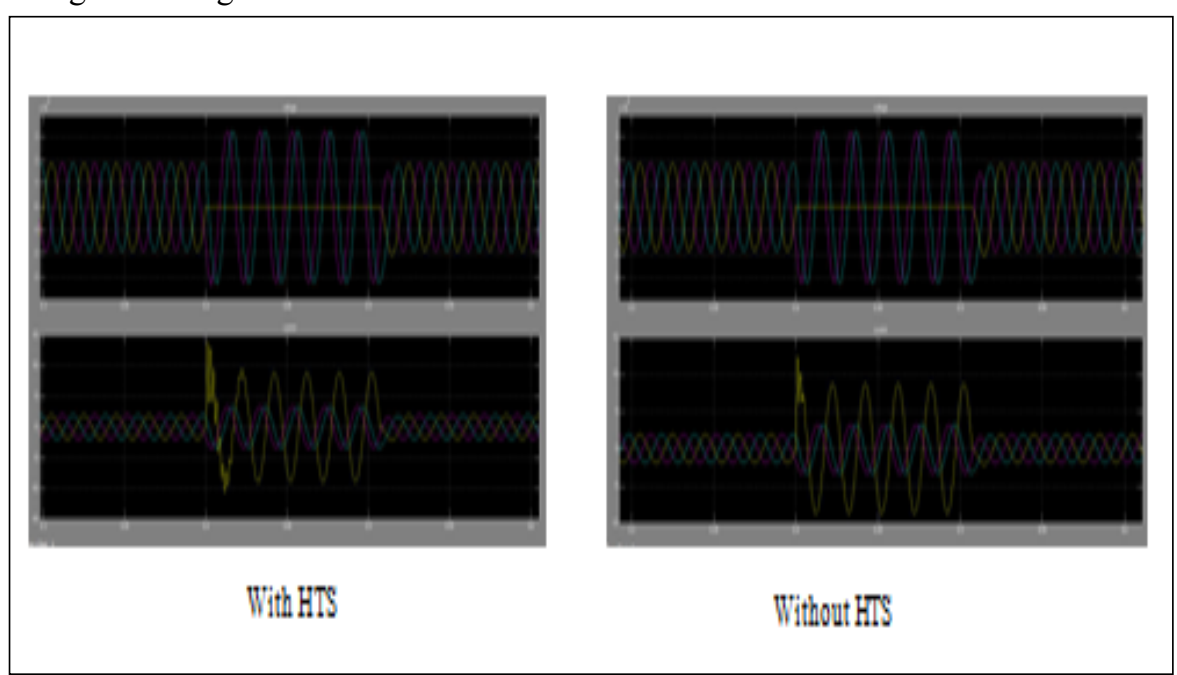

Figure.11 comparison of a single line to ground fault of HTS and without HTS cable

2) Line to Line fault

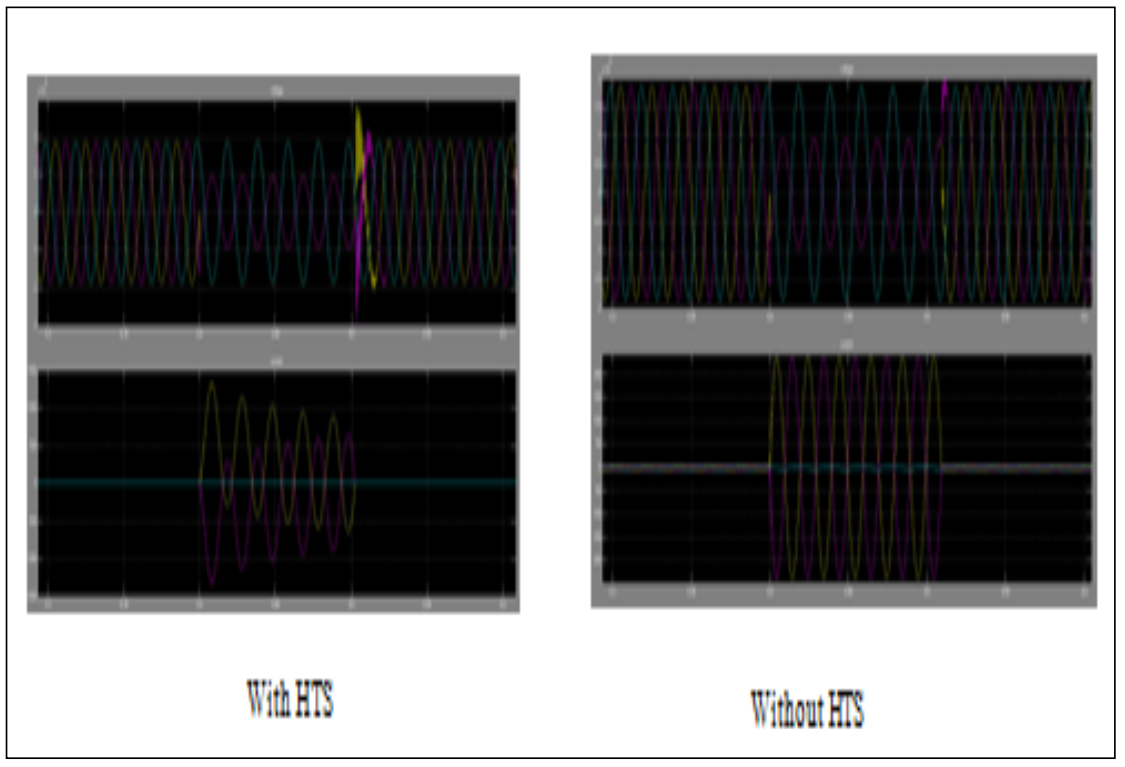

Figure.12 comparison of line to line fault of HTS and without HTS cable 
The HTS Cable Under Fault Conditions in a Power System Tarun Patel and Anuradha Deshpande

3) Double Line to ground fault

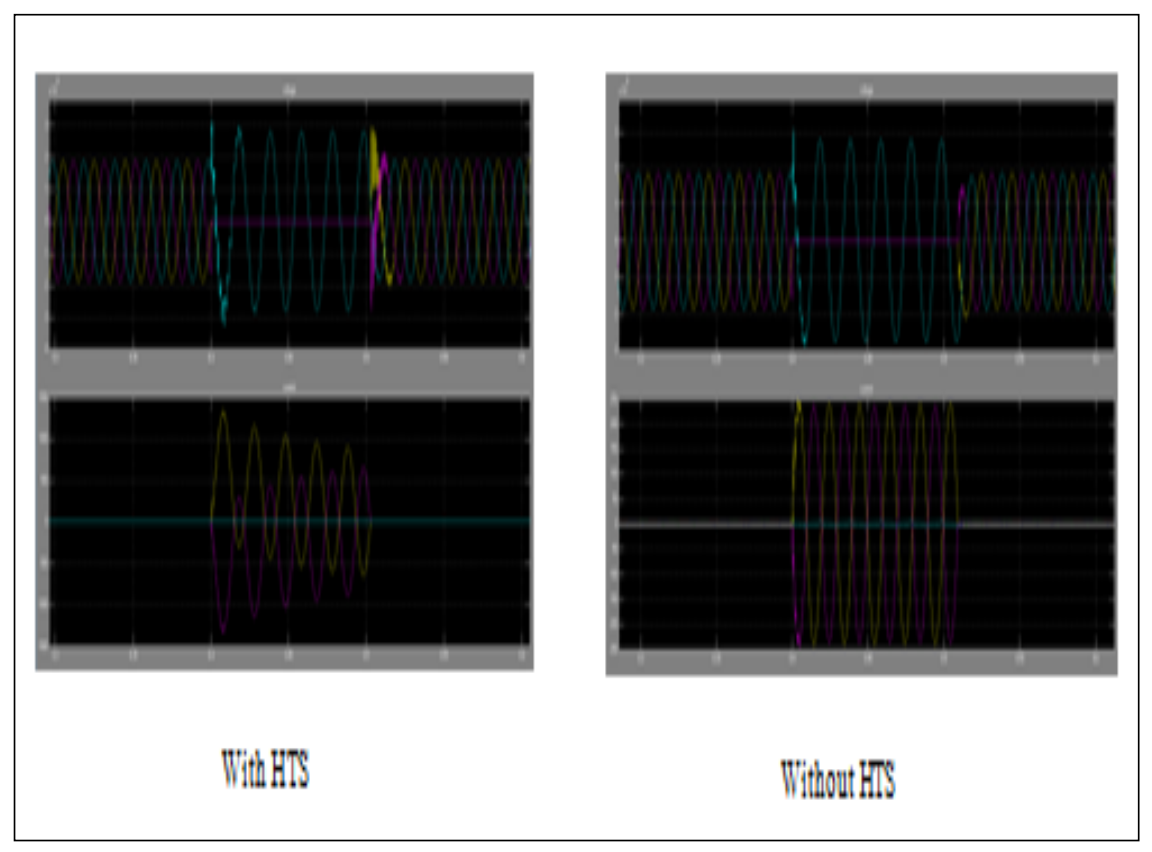

Figure.13 comparison of double line to ground fault of HTS and without HTS cable

4) Three phase fault

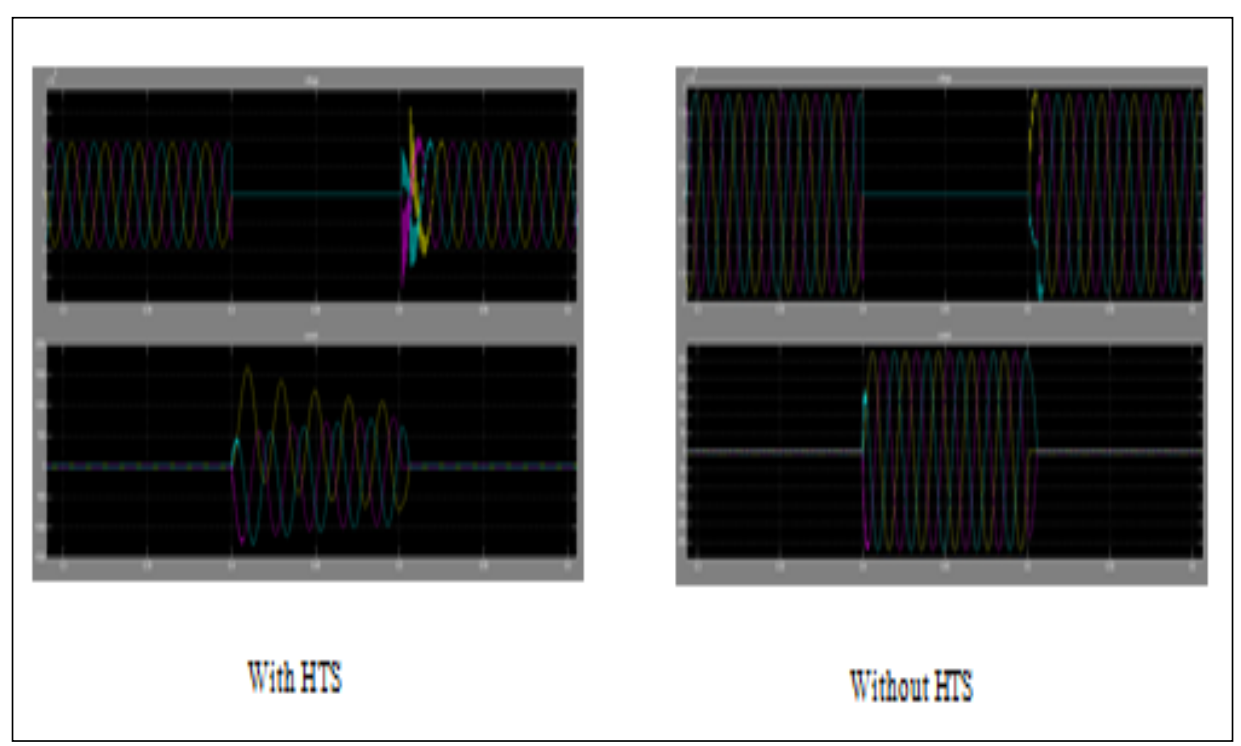

Figure.14 comparison of three phase fault of HTS and without HTS cable 
Table 2. COMPARISON OF THE DIFFERENT FAULT CONDITION

\begin{tabular}{|c|c|c|c|}
\hline $\begin{array}{c}\text { Type of } \\
\text { Fault }\end{array}$ & $\begin{array}{c}\text { Fault current } \\
\text { with HTS cable }\end{array}$ & $\begin{array}{c}\text { Fault current } \\
\text { without HTS cable }\end{array}$ & $\begin{array}{c}\text { Fault current by } \\
\text { ref.paper }\end{array}$ \\
\hline LG fault & $1.2 \mathrm{kA}$ & $0.24 \mathrm{kA}$ & $16.2 \mathrm{KA}$ \\
\hline LL fault & $3.5 \mathrm{KA}$ & $240 \mathrm{~A}$ & - \\
\hline LLG fault & $3.8 \mathrm{KA}$ & $242 \mathrm{~A}$ & - \\
\hline LLL fault & $4.7 \mathrm{KA}$ & $276 \mathrm{~A}$ & $8.1 \mathrm{KA}$ \\
\hline
\end{tabular}

Analysis suggests that use of HTS-FCL cable for protection application of power system.

\section{Conclusion}

Paper can conclude from above comparison that the fault current level of HTS cable is higher than that of three phase conventional AC cable under fault condition. Power transfer capacity of HTS cable is higher than conventional AC cable. Losses are low in HTS cable as compared to AC cable under normal operating condition. LLL or three phase fault is the most severe fault than the LG or LL or other asymmetrical fault. Also we can see that the three phase fault condition was extremely dangerous compare to any symmetrical fault condition. The reason of that is the peak fault current value is higher in asymmetrical fault condition than that of the symmetrical fault condition. Comparison with a standard IEEE paper using HTS cable is established.

\section{References}

[1] Jae-Ho Kim, Minwon Park, and In-Keun Yu, "Development of Real Time Protective Coordination Algorithm for HTS Power Cable" IEEE Trans. Appl. Supercond., vol. 25, no.3,p. 5401204,jun.2015.

[2] Hyung-Chul Jo,Seongbae Kong, and Sung-kwan Joo,"Impedance selection of fault current limiting supercunducting cable under fault condition in a power system from a system protection perspective"IEEE Trans.Appl.supercunductivity,vol.26,no.4,P.5400204, Jan.2016.

[3] Dongyeon Lee, Hyung-Chul Jo, Student Member, IEEE, and Sung-Kwan Joo, Member, IEEE, "Economic evaluation method for fault current limiting superconducting cables considering neywork congestion in a power system"IEEE Trans.Appl. Supercond. Vol.26, No.4, jun.2016.

[4] H. C. Jo, S. K. Joo, and K. Lee, "Optimal Placement of Superconducting Fault Current Limiters (SFCLs) for Protection of an Electric Power System with Distributed Generations (DGs)," IEEE Trans. Appl. Supercond., vol. 23, no. 3, p. 5600304, Jun. 2013.

[5] Hee Jin Kim, Student Member, IEEE, Jae Woong Shim, Kideok Sim, and Kyeon Hur, Senior Member, IEEE, "Assessment of improved power quality due to fault current limiting HTS cable" IEEE Trans.Appl. Superconductivity, Vol. 23, No.3,Jun 2013.

[6] J.Bock, A.Hobl, J.Schrmm, S.Kramer, and C.Janke, "Resistive Superconducting Fault Current Limiters Are Becoming a Mature Technology," IEEE Trans. Appl. Supercond., vol. 25, no. 3,Jun.2015.

[7] J. Maguire, D. Folts, J. Yuan, D. Lindsay, D. Knoll, S. Bratt, Z. Wolff, and S. Kurtz, "Development and Demonstration of a Fault Current Limiting HTS Cable to be Installed in the Con Edison Grid," IEEE Trans. Appl. Supercond., vol. 19, no. 3, pp. 1740-1743, Jun. 2009. 